\title{
Os Objetos Digitais de Aprendizagem aplicados no Ensino da Matemática
}

\author{
Maria da Conceição Jales Cavalcante, Welliana Benevides Ramalho \\ Universidade Federal Rural do Semi-Árido (UFERSA) \\ Angicos-RN, Brasil \\ \{mariajales_cavalcante@hotmail.com,welliana.ramalho@ufersa.edu.br\}
}

Resumo. Este artigo tem por objetivo contextualizar o papel das tecnologias e suas aplicações em sala com o ensino da matemática e seus desafios, e aplicar intervenções em uma escola no interior do estado do Rio Grande do Norte, utilizando Objetos Digitais de Aprendizagem (ODA). Para tal, foram necessárias leituras acerca do uso dos ODA no processo de ensino-aprendizagem, visitas à escola, para planejamento junto ao professor de matemática, escolha dos softwares a serem trabalhados e intervenções que encontram-se em andamento.

Abstract. This article aims to contextualize the role of technologies and their applications in the classroom with the teaching of mathematics and its challenges, and to apply interventions in a school in the interior of the state of Rio Grande do Norte using Digital Learning Objects (ODA). To do this, it was necessary to read about the use of ODA in the teaching-learning process, visits to the school, planning with the math teacher, choosing the software to be worked and interventions that are in progress

\section{Introdução}

Ao analisarmos a Estrutura Curricular da educação básica, disponibilizada pelo Governo do estado, é possível perceber que a matemática está entre as principais disciplinas a serem trabalhadas, uma vez que está entre as disciplinas com maior número de aulas.

A presente pesquisa tem como objetivo acompanhar os efeitos da inserção dos Objetos Digitais de Aprendizagem (ODA) como parte do processo de ensino da matemática, possibilitando assim uma melhor compreensão do conteúdo.

Ao final deste trabalho objetivamos comprovar os benefícios da utilização dos ODA, enquanto auxiliar no processo de fixação dos conteúdos propostos pelo currículo escolar, na disciplina de matemática.

\section{As dificuldades no Ensino da Matemática}

O ensino da matemática tem sido um desafio para os professores. Ao observar os índices de aprendizagem, referente ao ano de 2015, disponibilizados pelo Instituto Nacional de Estudos e Pesquisas Educacionais Anísio Teixeira (INEP) e graficamente disponíveis no QEdu, é possível perceber os baixos índices de aprendizagem na 
disciplina de matemática. Esses dados são fundamentados pela aplicação da Prova Brasil.

"Embora seja "moderno" o conteúdo ensinado, a maneira de apresentá-lo permanece às vezes arcaica do ponto de vista psicológico, enquanto fundamentada na simples transmissão de conhecimentos" (PIAGET,1975, p.19). Como é possível perceber na fala de (PIAGET,1975), o conteúdo é modernizado, mas a forma de trabalhar o mesmo em sala de aula é a mesma.

\section{As tecnologias digitais aplicadas à educação e seus desafios}

O uso das Tecnologias Digitais dentro da sala de aula associada ao Ensino, ainda é problema para muitos professores ao mesmo tempo vivemos um momento onde se faz necessário rever as práticas pedagógicas e a metodologia de ensino a fim de inserir as TIC's na educação. Porém, é necessário levar em consideração que a inserção das Tecnologias Digitais por si só não fará com que o aluno aprenda.

Para tal, temos os Objetos Digitais de Aprendizagem (ODAs), que são materiais digitais criados para auxiliar os alunos na compreensão dos conteúdos. Ao selecionarmos um ODA é necessário analisar suas características em suas perspectivas: pedagógica e física. No tocante aos aspectos pedagógicos devem ser avaliado se há interatividade entre o aluno e o Objeto em questão; se o mesmo propõe autonomia ao aluno; e, se motiva o aluno a aprender o conteúdo. Já no que diz respeito ao físico, deve-se observar se ele está disponível para uso; se é acessível a todos os usuários; dentre outros aspectos.

Os ODAs podem ser encontrados nos repositórios, espaços virtuais criados para armazenar os ODA, que dispõem de diversas ferramentas. Dentre os repositórios mais conhecidos, estão o Banco Internacional de Objetos Educacionais, Escola Virtual e Portal do Professor.

\section{Metodologia}

O desenvolvimento do trabalho foi dividido em etapas, elencadas a seguir:

- Visitas à escola;

- Escolha dos softwares a serem trabalhados;

- Criação dos planos de aula;

- Aplicação do plano de aula.

\subsection{Visita à escola}

Durante as visitas realizadas à referida escola observamos todo o espaço escolar, bem como a forma como este está organizado tanto fisicamente, quanto pedagogicamente, visando conhecer o ambiente escolar, e analisar de perto como ocorre a prática docente.

Identificamos que a escola possui um laboratório de informática com cerca de 20 (vinte) máquinas, porém encontra-se inativo, visto que os computadores apresentaram problemas no decorrer no ano letivo, por falta de manutenção.

\subsection{Escolha dos softwares a serem trabalhados}

Ao longo da escolha dos softwares, foi levado em consideração os assuntos propostos pelo professor de matemática, embasando-se nos conteúdos trabalhados em sala, no 
nível de conhecimento dos alunos acerca do uso das TIC's e nas características físicas e pedagógicas que devem se fazer presentes em um ODA, conforme citado anteriormente. Após uma análise, optamos pelo Combina e do Geogebra.

\subsection{Criação dos Planos de aula}

Os planos de aula foram criados em conjunto com o professor de matemática. Após a análise do conteúdo a ser trabalhado e a escolha dos ODA, estabelecemos os objetivos a serem atingidos. Em conformidade com o conteúdo de cada turma, foi criado um plano.

Espera-se que o discente ao fazer uso do Geogebra, seja capaz de interpretar e compreender as funções quadráticas, bem como identificar os dados que dão origem ao gráfico, de modo a assimilar a importância de cada valor presente na função.

No tocante a utilização do Combina, almeja-se que o discente possa extrair, dos problemas apresentados, as informações cruciais e com a utilização do software realizem o cálculo de Arranjo e Combinação. Este software é indicado para a fixação do conteúdo, uma vez que para utilizá-lo é ideal que o discente já possua conhecimento prévio acerca de como é feito o cálculo, tendo em vista que o mesmo só mostra a aplicação na fórmula e apresenta os resultados.

\subsection{Aplicação do Plano de aula}

Esta fase consiste na realização de intervenções junto a escola previamente escolhida e estudada, a fim de comprovar a importância da utilização dos ODA, no ensino da matemática. Até o momento, foram realizadas intervenções em apenas duas turmas do Ensino Médio.

Em virtude da inatividade do laboratório de informática, houve a necessidade de adequar o plano de aula as condições da escola, então optamos pela utilização de um projetor, onde por meio do notebook, seria possível promover uma interação entre os alunos e o software.

\subsubsection{Geogebra e o estudo de Funções Quadráticas ou Função de $2^{\circ}$ Grau}

O Geogebra é um software com versão gratuita para fins não comerciais, utilizado no ensino da matemática. Esse, faz uma junção dos conhecimentos de geometria e álgebra em uma única interface gráfica. É mais utilizado para trabalhar funções e gráficos, proporcionando aos alunos uma experiência mais prática, possibilitando aos seus usuários representar graficamente funções quadráticas no plano cartesiano, identificar parábolas, dentre outros. A área de trabalho do software em questão pode ser visualizada na Figura 1. 


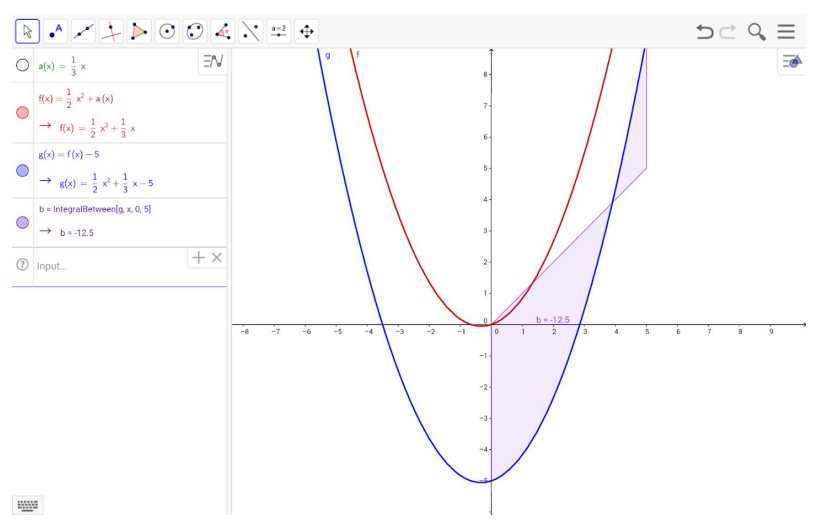

Figura 1. Interface do Geogebra

A intervenção teve por objetivo proporcionar aos alunos um momento mais prático durante o estudo das funções quadráticas. Iniciou-se com a aplicação de exemplos que já haviam sido trabalhados em sala, pelo professor de matemática.

Ao projetar o gráfico gerado pelas funções, os alunos poderiam sugerir alteração nos valores, buscando assim compreender a importância de cada valor, bem como analisar a alteração do gráfico. Partindo de um conhecimento teórico para um momento prático, onde foi possível observar e compreender a função de cada valor dentro de uma função, em relação ao gráfico formado no plano cartesiano.

\subsubsection{Combina e o estudo de Análise Combinatória}

O combina trata-se de um software Pago, porém com versão Demo, que permite aos usuários realizarem cálculos de análise combinatória (Arranjos, Combinação e Permutação) gerando as combinações possíveis. Na versão Demo serão exibidos apenas os 50 (cinquenta) primeiros resultados.

A interface pode ser observada na Figura 2.

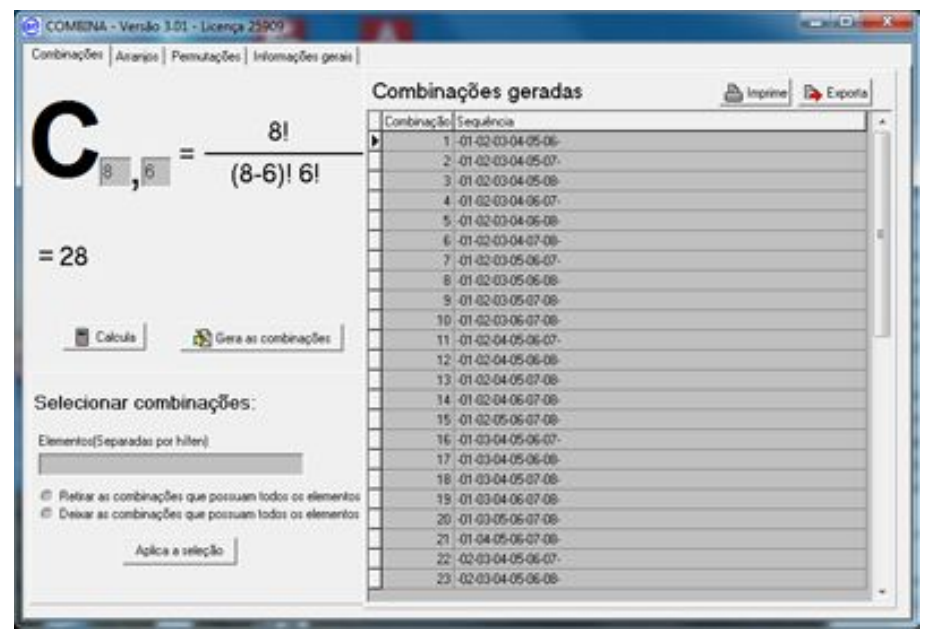

Figura 2. Interface do Combina 
A intervenção com a turma do $2^{\circ}$ ano a ação teve por objetivo introduzir um assunto que seria trabalhado posteriormente pelo professor. O conhecimento que os alunos possuíam era um conhecimento mais voltado para a própria multiplicação, mas já conseguiam resolver problemas referentes a arranjos, mesmo não associando o cálculo ao estudo propriamente dito. Ao utilizar o Combina em sala, trabalhamos exemplos associados ao cotidiano dos próprios alunos, a fim de torná-los parte do objeto de estudo, visando uma maior participação dos mesmos.

Foram exemplo simples com possibilidades bem limitadas e na medida em que os alunos foram interagindo e respondendo como o cálculo aconteceria no software e quais as informações o software iria utilizar para realizar os cálculos, aumentou-se o nível das perguntas, de modo que expandisse o número de possibilidades.

\section{Considerações Finais}

Feita a discussão acerca da contextualização da inserção das tecnologias em sala com o ensino da matemática e seus desafios, em consonância com as intervenções já realizadas na escola, observou-se uma maior participação por parte dos estudantes, uma vez que os software escolhidos se tornam atrativos para o aluno.

Durante as intervenções, os objetivos propostos no plano de aula foram alcançado, uma vez que os alunos interagiram e interpretaram os dados conforme proposto. Após a identificação dos dados, foi solicitado que os alunos aplicassem os dados nos softwares, onde demonstraram compreender como ocorre a utilização do mesmo.

Tendo em vista que houveram apenas duas intervenções, objetivamos a realização de outras, a fim de concluir nosso trabalho com o máximo de precisão, buscando fomentar os benefícios promovidos através da inserção das TIC's no ensino, em especial na disciplina de matemática.

\section{Referências}

BRAGA, Juliana C. Objetos de aprendizagem - volume 1: introdução e fundamentos. Santo André: Editora da UFABC, 2014.

SECRETARIA DA EDUCAÇÃO E DA CULTURA. Disponível em: $<$ http://www.educacao.rn.gov.br/Conteudo.asp?TRAN=ITEM\&TARG=169240\&AC $\mathrm{T}=\& \mathrm{PAGE}=\& \mathrm{PARM}=\& \mathrm{LBL}=\mathrm{NOT} \% \mathrm{CDCIA}>$ Acesso em: 30 de Nov de 2018

ADISIO RIBEIROS WEBSITE. Disponível em:
$<$ http://www.adisioribeiro.com.br/combina.htmll> Acesso em: 30 de nov de 2018

BANCO INTERNACIONAL DE OBJETOS EDUCACIONAIS. Disponível em: $<$ http://objetoseducacionais2.mec.gov.br/>. Acesso em: 03 de Setembro de 2018.

PORTAL DO PROFESSOR. Disponível em: <http://portaldoprofessor.mec.gov.br/> Acesso em: 06 de set de 2018.

OKUMA, E. K. Ensino e a aprendizagem da matemática: por que a aversão a respeito da disciplina?. UniSalesiano, 2009. Disponível em: http://www.unisalesiano.edu.br/encontro2009/trabalho/aceitos/CC46511180115.pdf. Acesso em: 06 de set. de 2018. 
QEDU. Disponível em: <http://www.qedu.org.br/brasil/proficiencia> Acesso em: 06 de set de 2018

GEOGEBRA. Disponível em: <https://www.geogebra.org/?lang=pt> Acesso em: 07 de set. de 2018.

GEOGEBRA. Disponível em: <https://www.geogebra.org/license> Acesso em: 30 de nov. de 2018. 